\title{
HABITAÇÃO SOCIAL EM PRESIDENTE EPITÁCIO-SP E QUESTÕES URBANAS
}

Rafaela Mussolini Celestino de Oliveira', Mayara Mota Cordeiro Souza', Sibila Corral de Arêa Leão Honda $^{2}$, Marcela do Carmo Vieira ${ }^{2}$

${ }^{1}$ Discentes do curso de Arquitetura e Urbanismo da Universidade do Oeste Paulista - UNOESTE. 2 Docentes do curso de Arquitetura e Urbanismo da Universidade do Oeste Paulista

\section{RESUMO}

O processo de urbanização brasileiro possibilitou o surgimento de sérios problemas urbanos e sociais, sendo a favela um dos mais profundos. Essa característica de moradia urbana não se resume, no entanto, às grandes cidades; podendo ser identificadas ocupações ilegais e processos de favelização também em cidades de portes médio e pequeno. $O$ descaso político, de planejamento e de gestão possibilitam sua implantação e reprodução. Ações dos Poderes Públicos por meio de projetos de desfavelização, remoção da população e entrega de habitações sociais adequadas precisam ser reforçados. A partir desse perfil, este artigo busca demonstrar a existência de favela em cidade de pequeno porte e ações públicas assumidas para remoção de sua população. O foco de estudo é Presidente Epitácio, no interior do Estado de São Paulo. A metodologia assumida foi de verificação de campo, e levantamentos bibliográficos e documentais. Palavras-chave: Habitação Social, Planejamento Urbano, Expansão Urbana, Projeto Urbano, Segregação Socioespacial Urbana.

\section{INTRODUÇÃO}

O processo de urbanização que acontece no Brasil nas últimas oito décadas tem ocasionado sérios problemas urbanos, e principalmente habitacionais. Verifica-se a propriedade urbana concentrada nas mãos de poucos, e a não utilização de instrumentos urbanísticos que possibilitam controle e democratização do solo urbano. Esse quadro não ocorre apenas nos grandes centros urbanos, sendo reproduzido e reforçado nas cidades de portes médio e pequeno.

$E$, desde o fim do século XIX, podem ser notados sérios problemas de acesso à habitação digna no país, com reprodução da segregação socioespacial (BONDUKI, 2004). Atualmente, a cidade ilegal, ou seja, as áreas não legalizadas da cidade, continua crescendo, reforçando os sérios problemas da urbanização brasileira, apoiada na falta de controle urbano e da carência de oferta de habitação legal e digna.

A partir de 1930, no Brasil, durante a "Era Vargas", o Estado começou a desenvolver políticas de modernização do país, além de tentar ganhar apoio popular com atendimento de diversos aspectos da vida urbana, inclusive a área habitacional. Em 1945, o governo federal passou 
a buscar uma política habitacional nacional descentralizada, com construção de grandes conjuntos de apartamentos, em âmbito nacional (SACHS,1999).

No início da década de 1960, durante o governo de Jânio Quadros, buscou-se uma reestruturação na política habitacional, por meio de linhas de ação de curto e longo prazos, mas que não saiu do papel por questões políticas. E, ao mesmo tempo, o processo de urbanização no país ocorria com grande intensidade, gerando crescimento da demanda por moradias, agravando a situação habitacional brasileira; além do processo inflacionário e leis populistas no mercado de aluguéis, que causaram diminuição de investimentos no setor (HONDA, 2011).

Em 1964, com o regime militar, a política habitacional foi extinta, tendo sido lançada uma nova, que, em teoria, buscava facilitar o acesso à casa própria, e o Banco Nacional da Habitação (BNH) foi criado como agente financiador. De forma geral, os locais em que conjuntos habitacionais foram executados eram distantes e sem qualquer infraestrutura ou equipamento urbano, criando sérios problemas para os moradores e para o Poder Público municipal.

A espacialização periférica dos conjuntos do BNH, aliada à sua grande dimensão, gerou uma transformação na estrutura e na paisagem urbana da maioria das cidades brasileiras. Esse modelo de implantação perdurou até os primeiros anos da década de 1990, no governo de Fernando Collor de Melo. A partir do Governo Militar, ocorreram significativas alterações políticas com crescente importância do papel do Estado, e políticas elitistas e excludentes, reforçando e reproduzindo a segregação socioespacial nas cidades (KOWARICK, 1994).

O período seguinte é caracterizado pela crise do modelo de política habitacional, com fragilidade das propostas voltadas ao enfrentamento dos problemas da moradia; e em 1986 o BNH foi extinto. Em 1988 a nova Constituição Federal foi sancionada, com capítulo sobre política urbana e igualando o Município aos outros entes federativos (União e Estados), com atribuições específicas, como o controle do espaço urbano, e comuns, como a oferta de moradia.

A partir de então, a preocupação municipal com políticas urbanas passou a ser central, visando à busca pelo "[...] desenvolvimento sustentável dos assentamentos humanos e a aquisição de abrigo adequado para todos", segundo o programa UN-Habitat (ANTONUCCI, 2009, p.4).

No entanto, como já foi dito, por incapacidade de investimentos suficientes e de controle e gestão, em âmbitos municipal, estadual e federal, tem havido forte processo de ocupação de áreas de forma ilegal, sem a propriedade da terra, e com ocupação não regulada; com predominância em locais periféricos. Essa realidade atinge os centros urbanos de forma democrática, ou seja, pode ser observada nos grandes, médios e até pequenas cidades. 
O processo de favelamento tem se expandido. E entende-se favela como "espaço específico não apenas geográfico como também social, que vem engrossando a cidade ilegal"; assim como espaço "homogêneo, marcado pela irregularidade na ocupação do solo e precariedade em termos de serviços públicos e equipamentos urbanos" (PRETECEILLE e VALLADARES, 2000, p.460).

A partir disso, esta artigo busca apresentar a realidade da cidade de Presidente Epitácio, no interior do Estado de São Paulo, que teve formação de favela urbana. A pesquisa que embasa este artigo possibilitou compreender a desfavelização que ocorreu na cidade, por meio de entrega de unidades habitacionais urbanas em conjunto habitacional executado próximo à antiga favela.

\section{METODOLOGIA}

A metodologia utilizada nesta pesquisa está baseada em análises e sínteses recorrentes e sucessivas, por meio de etapas de investigação científica simples e objetiva. Inicialmente, a pesquisa aprofundou a linha teórica. E, a partir de então, ocorreu a investigação prática, com análise do caso estabelecido.

\section{PRESIDENTE EPITÁCIO-SP - IDENTIFICAÇÃO ESPACIAL URBANA}

A Estância Turística de Presidente Epitácio localiza-se no limite do Estado de São Paulo, às margens do Rio Paraná. A região começou a ser conhecida a partir de 1888 devido à passagem do gado trazido de Mato Grosso.

Com a criação de currais para gado e pousos para quem ali passava, em 1907 foi fundado o Porto Tibiriçá. Em 1919 ocorreu a chegada dos trilhos da Estrada de Ferro Sorocabana, cujo tráfego ferroviário, iniciado em maio de 1922, marcou a data de fundação da cidade (GODOY, 2012).

O município apresenta atualmente mais de 41mil habitantes (Censo 2010), destacando-se também por ser uma estância turística, o que resulta em necessidades específicas em relação ao controle e ao planejamento do espaço municipal, por meio de Plano Diretor Municipal.

Apesar de ser uma cidade pequena, Presidente Epitácio possui problemas relacionados à infraestrutura urbana, inclusive com formação de favela urbana, a Vila Casquinha, localizada na área norte do município, com a presença de 60 famílias. 
Após a parceria da Prefeitura Municipal e do Governo Federal, por meio do programa "Minha Casa Minha Vida", foi construído um novo conjunto habitacional chamado Vila Nova, para a recolocação das famílias que moravam na Vila Casquinha, sendo que todas as casas tiveram custo zero para as famílias. Esse novo conjunto habitacional foi construído próximo à Vila Casquinha, e entregue em setembro de 2012 (Figura 1).

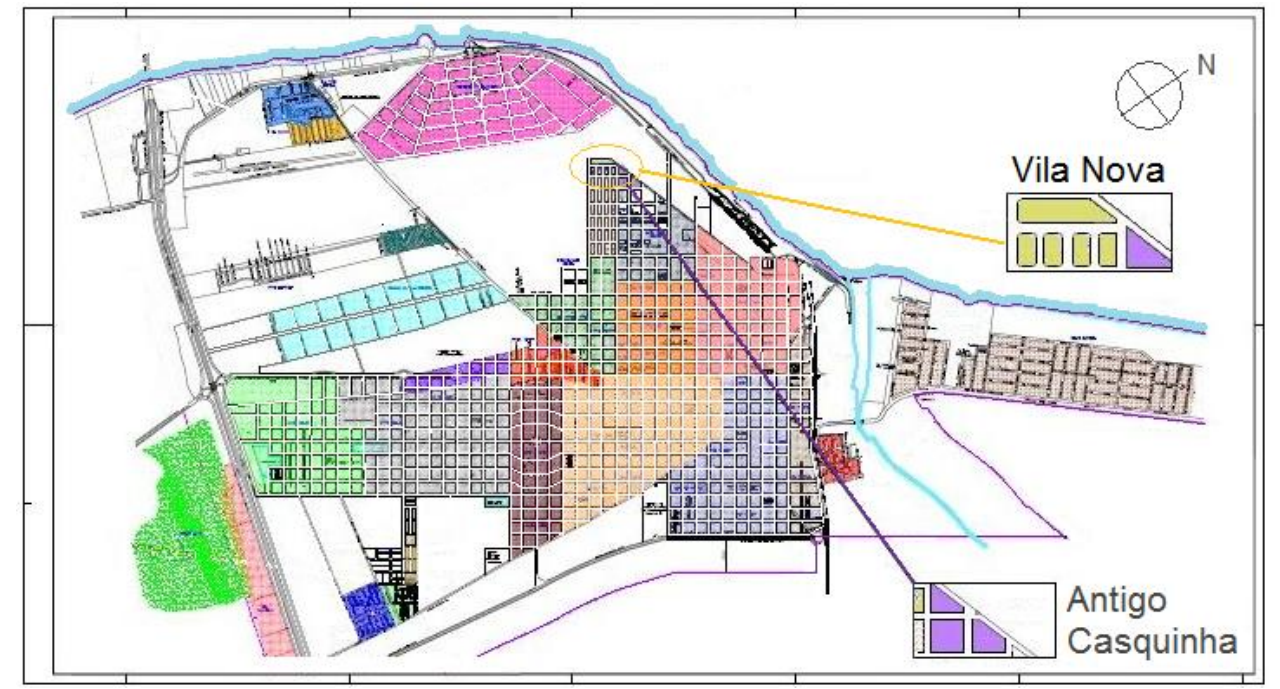

Figura 1. Localização da antiga favela e do conjunto habitacional Fonte: Prefeitura Municipal de Presidente Epitácio, 2013

\section{FAVELA - SIGNIFICADO URBANO}

O surgimento do processo de favelização não é consenso entre estudiosos, mas há forte entendimento que teria se iniciado a partir da década de 1930. A favela é termo associado à ocupação ilegal, com moradias precárias, e carente de infraestruturas e serviços urbanos; tornando-se consensual o significado de favela igual a pobreza (PRETECEILLE e VALLADARES, 2000).

Também é importante notar que a favela não é uma comunidade isolada, dependendo diretamente de certas condições estruturais da sociedade, e reproduz a segregação urbana de forma clara (SILVA, 2011).

A segregação, por sua vez, na estrutura urbana brasileira, está baseada principalmente nas questões econômicas e de classes sociais. Ou seja, a segregação pode ser entendida como um processo no qual pessoas de mesma classe social tendem a se concentrar em determinadas regiões ou conjuntos de bairros, resultando em segregação socioespacial (VILLAÇA, 1998).

Importante notar também que o reforço da segregação socioespacial está na carência ou ausência de serviços públicos, distando desses equipamentos e serviços urbanos, fazendo com que o espaço atue como mecanismo de exclusão. Assim, a segregação é processo necessário à dominação social e econômica por meio do espaço (VILLAÇA, 1998). 


\section{DESFAVELAMENTO EM PRESIDENTE EPITÁCIO}

A favela Casquinha existente em Presidente Epitácio abrigada 60 famílias, localizandose na região noroeste da malha urbana dessa cidade. Estava implantada em área pública municipal, de uso de lazer e área verde. A proibição legal federal de alteração de uso do solo urbano não permitiria a legalização da área com transferência de propriedade a seus ocupantes.

Embora localizada dentro da malha consolidada, em local com infraestrutura urbana, os moradores dessa favela não eram beneficiados com tais serviços. Apesar da cidade ser de pequeno porte, os problemas estruturais nacionais também a atingem, tendo resultado na invasão de área e favelização.

No entanto, no final de 2009, uma parceria entre a Prefeitura Municipal de Presidente Epitácio e o Governo Federal foi firmada, por meio do programa "Minha Casa Minha Vida"; tendo sido projetadas e construídas 60 unidades residenciais para remoção dessa população favelada.

Importante destacar alguns aspectos. A remoção da população para unidades de moradia construídas em alvenaria, com alguns dos serviços de infraestrutura urbana, é de extrema relevância, beneficiando sua população carente. Entretanto, o descaso público ainda pode ser bastante observado.

Não há presença de calçadas, muito menos de asfalto nas ruas, havendo ausência de lixeiras e sinalizações (Figura 2). Não há presença de parque ou algum tipo de praça para uso coletivo e público. E, por ser um conjunto habitacional voltado para população carente, com renda familiar de menos de três salários mínimos, o meio de transporte mais utilizado entre eles é a bicicleta, principalmente porque não há ônibus urbano de transporte coletivo.

As edificações construídas onde se localizava a favela foram completamente derrubadas, podendo ser identificado o antigo espaço para implantação de área de lazer (Figura 3). A localização do novo loteamento onde foi construído o conjunto de habitação de interesse social é bastante perto da área da favela, possibilitando à sua população a permanência das características de vida e vizinhança; embora reproduza a segregação socioespacial por não ter havido inclusão na estrutura urbana consolidada. 


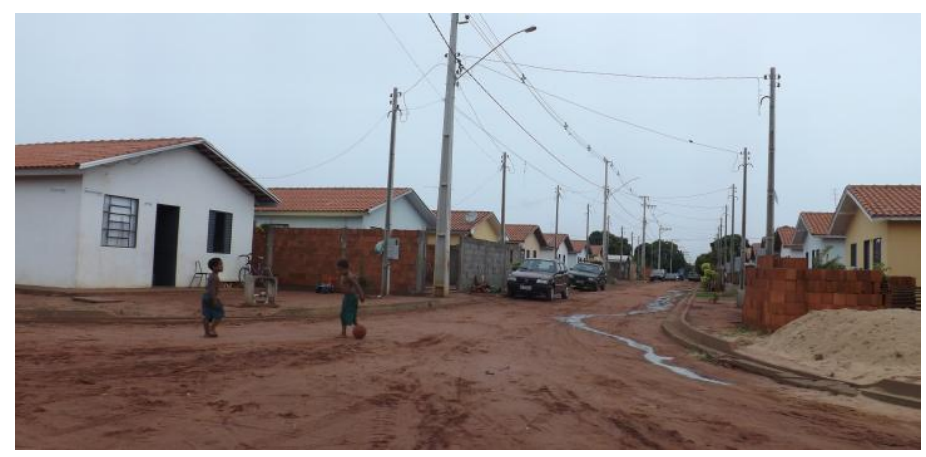

Figura 2.- imagem do conjunto habitacional executado

Fonte: autoras, 2013

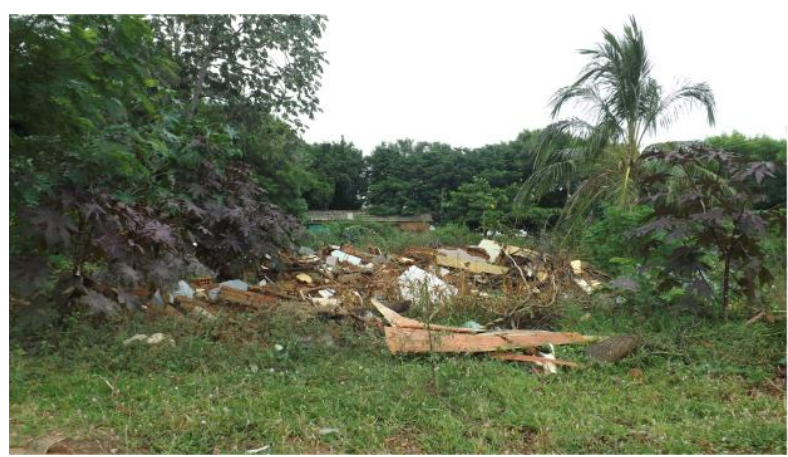

Figura 3. imagem do local onde estava localizada a favela Casquinha Fonte: autoras, 2013

As unidades residenciais mantiveram um processo de implantação padrão, com mesma tipologia construída, e projeto único dessas unidades. Cada residência possui dois dormitórios, um banheiro, e uma sala integrada com cozinha, com 32,37 $\mathrm{m}^{2}$ de área construída (Figura 4). O projeto original já previu possibilidades de ampliação das unidades, o que tem ocorrido.

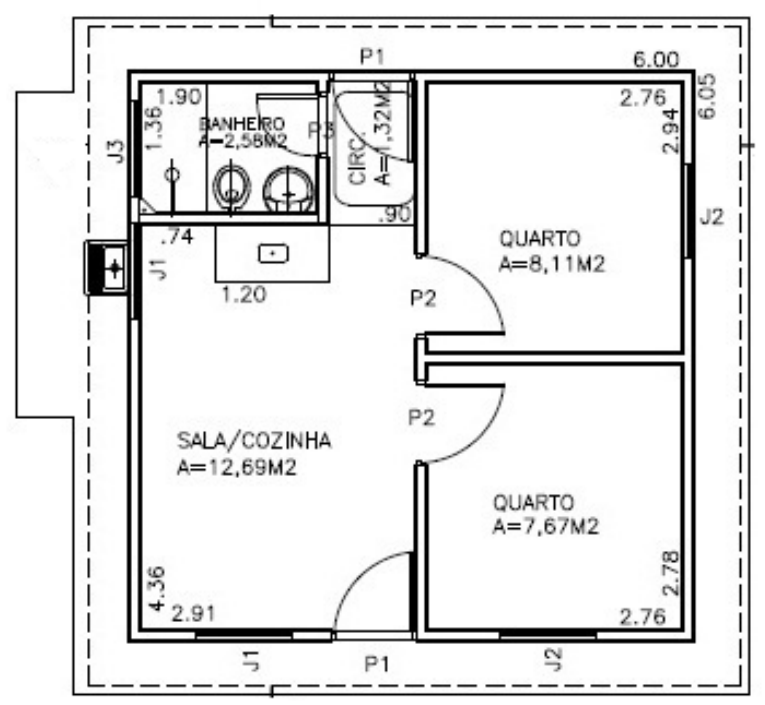

\section{PLANTA}

Figura 4. planta padrão das unidades residenciais - processo de aprovação - fev/2010 Fonte: Prefeitura Municipal de Presidente Epitácio, 2013 


\section{CONSIDERAÇÕES FINAIS}

A atenção que deve ser dada aos processos urbanos, de ocupação, de expansão, sociais, entre outros, deveria sempre ser bastante grande. O Poder Público local tem a competência para controle, planejamento e gestão do desenvolvimento urbano segundo a Constituição Federal de 1988; e deve cumprir tal responsabilidade.

Neste artigo foi apresentada a existência de favela no município de Presidente Epitácio, cidade de pequeno porte no extremo oeste do Estado de São Paulo; demonstrando que, independente do tamanho da cidade, o descaso público, além de gerar e reproduzir segregação socioespacial, favorece sua criação.

Nessa cidade, no entanto, por vontade política local, ocorreu projeto de desfavelamento, reintegrando sua população à cidadania. Apesar de ainda ser identificado que essa população carece de serviços e equipamentos públicos.

Assim, novas ações precisam ser realizadas, mas o início já ocorreu.

\section{REFERÊNCIAS}

ANTONUCCI, D. ONU e 30 anos do UN-Habitat. $5^{\circ}$. Fórum de Pesquisa FAU-Mack. São Paulo: UPM, 2009.

BONDUKI, N. Origens da habitação social no Brasil: arquitetura moderna, lei do inquilinato $e$ difusão da casa própria. $4^{\mathrm{a}}$.ed. São Paulo: Estação Liberdade, 2004.

GODOY, B. História de Presidente Epitácio. Presidente Epitácio: Editado pelo próprio, 2012.

HONDA, S.C.A.L. Habitação de Baixa Renda como Produto do Capital - o Programa de Arrendamento Residencial (PAR) em Presidente Prudente-SP. São Paulo: UPM, 2011 (Tese de Doutorado).

KOWARICK, L. As lutas sociais e a cidade: repensando um objeto de estudo. In: KOWARICK, L. (org.). As lutas sociais e a cidade: São Paulo - passado e presente. 2a. ed.rev. São Paulo: Ed. Paz e Terra, 1994.

PRETECEILLE, E.; VALLADARES, L. A desigualdade entre os pobres - favela, favelas. In: WERTHEIN, J.; NOLETO, M.J. (org). Desigualdade e pobreza no Brasil. São Paulo: UNESCO, 2000. Disponível em: http://www.empreende.org.br/pdf/Programas\%20e\%20Pol\%C3\%ADticas\%20Sociais/Desigualdade \%20entre\%20os\%20pobres\%20-\%20favelas.pdf. Acesso em 09 abr 2013.

SACHS, Celine. São Paulo: políticas públicas e habitação popular. São Paulo: EDUSP, 1999.

SILVA, L.A.M. A política na favela. In: Dilemas - Revista de Estudos de Conflito e Controle Social. V.4. n.4. out/nov/dez 2011. pp.699-716. Disponível em: http://revistadil.dominiotemporario.com/doc/DILEMAS-4-4-Art6.pdf. Acesso em 25 jun 2013. 
Encontro de Ensino, Pesquisa e Extensão, Presidente Prudente, 21 a 24 de outubro, 2013

VILLACA, F. Espaço Intra-Urbano no Brasil. São Paulo: Nobel, 1998. 